\title{
The outcome of patients with inflammatory bowel disease-associated colorectal cancer is not worse than that of patients with sporadic colorectal cancer-a matched-pair analysis of survival
}

\author{
Francesco Vitali ${ }^{1}$ (D) Axel Wein ${ }^{1} \cdot$ Timo Rath $^{1}$ (D) Markus Eckstein ${ }^{2} \cdot$ Clemens Neufert $^{1}$ (D) Jürgen Siebler ${ }^{1}$ (D) . \\ Raja Atreya ${ }^{1}$ D . Arndt Hartmann ${ }^{2} \cdot$ Werner Hohenberger $^{3} \cdot$ Klaus Weber $^{3} \cdot$ Markus Friedrich Neurath $^{1}$ (D) . \\ Robert Grützmann ${ }^{3} \cdot$ Susanne Merkel $^{3}$ (ID
}

Accepted: 22 November 2021 / Published online: 4 December 2021

(c) The Author(s) 2021

\begin{abstract}
Purpose Patients with inflammatory bowel disease (IBD) have an increased risk for colorectal cancer (CRC). In IBD patients, cancer is often diagnosed in advanced stages and conflicting data on survival compared to sporadic CRC have been reported. The aim of this study was to directly compare clinical characteristics and prognosis of patients with IBD-CRC and sporadic CRC.

Methods The clinical and pathological data of 63 patients with IBD-CRC and 3710 patients with sporadic CRC treated at the University Hospital of Erlangen between 1995 and 2015 were compared. Forty-seven M0 patients with IBD were matched with sporadic CRC patients after curative resection (R0) according to tumor localization, stage, sex, and year of treatment. Overall and disease-free survival were compared.

Results Sixty-three patients presented IBD-CRC. Fifty were affected with ulcerative colitis (UC) and 13 with Crohn's disease (CD). CRC was diagnosed within 1.45 years since last endoscopic surveillance. Twelve patients (19\%) had a diagnosis of primary sclerosing cholangitis. In matched analysis, IBD patients were diagnosed with CRC at younger age compared to sporadic CRC and were more likely to have right-sided CRC (40\% versus $23.3 \%$ ) and rare histological subtypes (19\% versus 9.2\%). No differences in 5-year overall (78.7 versus 80.9 months) and 5-year disease-free survival (74.5 versus 70.2 months) were noted.

Conclusion IBD-CRC patients were younger and more frequently had right-sided carcinomas compared to sporadic CRC. CRC in IBD patients did not show survival difference compared to matched-pair sporadic CRC patients without distant metastases after curative resection. Surveillance might be important for early detection of CRC in IBD patients.
\end{abstract}

Keywords Inflammatory bowel disease · Colorectal cancer $\cdot$ Ulcerative colitis · Crohn's disease

\section{Introduction}

Francesco Vitali

francesco.vitali@uk-erlangen.de

1 Department of Internal Medicine 1, Friedrich-AlexanderUniversity Erlangen-Nuremberg, Ulmenweg 18, 91054 Erlangen, Germany

2 Institute of Pathology, Friedrich-Alexander-University Erlangen-Nuremberg, Ulmenweg 18, 91054 Erlangen, Germany

3 Department of General and Abdominal Surgery, Friedrich-Alexander-University Erlangen-Nuremberg, Ulmenweg 18, 91054 Erlangen, Germany
Inflammatory bowel disease (IBD) is an established risk factor for the development of colorectal cancer (CRC) [1, 2]. Enhanced risk of CRC in IBD is associated with the severity and duration of inflammation, extent of disease (particularly in cases of pancolitis), smoking, family history of CRC, or the presence of primary sclerosing cholangitis [2-7]. As shown in several reports including prospective trials, the risk of colorectal cancer in UC is related to the cumulative inflammatory burden (CIB) as a feature of active endoscopic and histological inflammation [8-12].

Although an early meta-analysis of 116 studies has estimated a cumulative risk in ulcerative colitis of $18 \%$ 
after 30 years of disease duration [4], more recent studies noted a lower cancer incidence. As such, the excess CRC risk of 2.4 [13] has been estimated. For those patients with colonic Crohn's disease, the CRC risk has been estimated at a standardized incidence ratio (SIR) of 1.9 [14]. The patchy distribution of CD could explain the lower CRC risk compared to patients with UC. However, the risk of CRC in long-standing Crohn's colitis patients is comparable to those with UC, since a meta-analysis of data from population-based studies found a pooled SIR for CRC of 1.7 (95\% confidence interval, 1.2-2.2) in all patients with IBD [15]. The prospective CESAME Cohort confirmed an increased SIR of 7.0 for CRC in patients with long-standing extensive colitis [8]. According to a national nationwide study, patients with IBD who were diagnosed with CRC were younger than sporadic CRC counterparts $[16,17]$. They were also more likely to have multiple neoplastic lesions and had higher proportions of superficialtype lesions and invasive-type lesions at histology, as well as mucinous or signet ring cell histotypes [17].

Among IBD patients, cancer may develop as a result of chronic inflammation, leading to dysplasia and then to carcinoma $[18,19]$. Based on this mechanism of colitis-associated carcinogenesis, precancerous lesions in IBD are frequently heterogeneous and both histologically and molecularly different from sporadic colorectal carcinogenesis [20]. Commonly referred to as "field effect " or "field cancerization," inflammatory changes lead to a positive selection of heterogeneous genetic mutations resulting in a multitude of variants of colitis-associated precancerous lesions in which molecular alterations develop in normal-appearing tissue and expand into premalignant patches with the potential to progress to dysplasia and carcinoma [21,22]. At the same time, most of the molecular dysregulations occurring in sporadic colorectal carcinogenesis are also detected in IBD-associated CRC; however, marked differences in both its timing and prevalence have been noted. Recent studies in surgical specimen revealed frequent early loss or overexpression of the oncogene p53, early KRAS mutation, infrequent BRAF mutation [20], presence of aneuploidy [23], MGMT (O6-alkylguanine DNA alkyltransferase) loss [24], and MMR deficiency in about $10 \%$ of cases $[25,26]$. DNA methylation may also account for differences in presentation and outcomes between inflammatory bowel disease-associated carcinomas and sporadic CRC [27]. Molecular pathophysiological mechanisms of colitis-associated cancer are unclear; however, in a mouse model, the epiregulin/ERK (extracellular signal-regulated kinase) pathway appears to be particularly relevant for inflammation-associated colorectal carcinomas because mucosal inflammation results in marked production of potent epiregulin stimulators such as TNF-alpha and LPS (lipopolysaccharide-microbial proteins and pro-inflammatory molecules) [28].
Although many data on the risk factors for developing CRC in IBD patients and about strategies for prevention and early detection of CRC in IBD patients are available, knowledge about the presentation, treatment, and outcomes of CRC in IBD are scarce to date. Overall survival after CRC diagnosis in IBD patients is primarily determined by age, comorbidities, and cancer stage at diagnosis [1]. In the literature, IBD patients are found to be affected with CRC at younger age, are more often diagnosed in advanced stage, and have significantly decreased survival compared to sporadic CRC [29, 30]. However, Ali et al. could demonstrate in a propensity score matching analysis that the survival times of CRC patients with and without IBD were not significantly different [16].

Based on this, we set off to directly compare clinical characteristics and prognosis of patients with IBD-associated $\mathrm{CRC}$ and sporadic carcinogenesis.

\section{Patients and methods}

The study was designed as a retrospective analysis of a prospectively maintained data from the Erlangen Registry for Colorectal Carcinoma (ERCRC), Department of Surgery, Erlangen, Germany. The study was based on data from 1 January 1995 to 31 December 2015. General epidemiologic data, clinical findings, treatment, and follow-up data were collected prospectively. When performed, data about molecular pathology findings inclusive analysis for microsatellite instability were recorded. The Eastern Cooperative Oncology Group (ECOG) performance status (PS) was recorded before resection of the primary tumor. Follow-up data were collected either at the university hospital or from review of written correspondence with the patients' primary care physicians and specialists in gastroenterology and oncology. This study was approved by the Clinical Ethics Committee of the Friedrich-Alexander-Universität Erlangen-Nürnberg (FAU) (file number: 132_20 Bc).

Inclusion criteria for the study were as follows: age $>=18$ years, patients with inflammatory bowel diseaseassociated (Crohn's disease, ulcerative colitis) colorectal carcinomas and sporadic carcinomas who underwent radical surgery with TME or CME [31, 32] between 1995 and 2015. Exclusion criteria were appendix carcinoma and for the matched-pair analysis metastatic CRC (stage IV) and non-curative resection.

Carcinomas were classified according to the UICC/AJCC 8th edition [33, 34]. Tumor classification of histomorphology followed the rules of the WHO [35]. Localization within the colorectum was subdivided into right colon (from the caecum to the proximal two-thirds of the transverse colon), left colon (from the distal third of the transverse colon to the sigmoid colon), and rectum. 
The Clavien-Dindo classification was used to categorize postoperative complications [36].

\section{Matching}

Patients with IBD-associated CRC were matched with patients with sporadic CRC according to the following factors: pathological $\mathrm{T}$ and $\mathrm{N}$ categories (UICC stage I-III), sex, ECOG performance status, and localization of the neoplasm. Because sporadic colorectal cancer without known genetic predisposition in younger age is a rarity, matching for age 1:1 at time of diagnosis was impossible, so the best possible matching individual was included. The matchedpair analysis also considered the year of treatment \pm 5 years. A matching partner was found for 47 of the 48 IBD patients (M0, R0).

\section{Statistical analysis}

Categorical data were compared using the chi-squared test, and when appropriate ( $\leq 5$ patients within a group), the Fisher exact test was used. For comparison of continuous data, the Mann-Whitney $U$ test was applied. The survival analysis was performed using the Kaplan-Meier estimation with the date of initiation of tumor-related therapy (resection or neoadjuvant therapy) as starting point. Overall and disease-free survival curves for both groups were compared using the log-rank test. For disease-free survival curves, an event was defined as the first occurrence of locoregional recurrence, distant metastases, or death from any cause. A $p$-value less than 0.05 was considered significant. Analyses were performed using the IBM® SPSS $®$ Statistics 24.0 software package (Armonk, NY, USA).

\section{Results}

We identified a total of 63 patients with IBD-related CRC (Table 1). Fifty patients were affected with UC and 13 with CD.

Overall, IBD patients were diagnosed with CRC younger than patients with sporadic CRC (about 20 years earlier; Table 2). IBD patients presented more frequently with a right-sided CRC (40\% versus $23.3 \%$ ) and presented more
Table 1 Patient characteristics of 63 patients with IBDassociated colorectal carcinoma

\begin{tabular}{|c|c|c|c|}
\hline Number of total: 63 pts & $\begin{array}{l}\text { Ulcerative colitis } \\
(n=50)\end{array}$ & Crohn disease $(n=13)$ & \\
\hline $\operatorname{Sex}(M / F)$ & $29 / 21$ & $6 / 7$ & $P=0.444$ \\
\hline Alter & $49.0( \pm 16.7)$ & $43.2( \pm 9.9)$ & $P=0.132$ \\
\hline BMI & $27.9 \pm 11$ & $22.6 \pm 3.6$ & $P=0.173$ \\
\hline Smoking (> 5 Py) & $1(0.2 \%)$ & $4(30 \%)$ & $P=0.004$ \\
\hline Years of disease & $18.5( \pm 9.9)$ & $19.0( \pm 5.9)$ & $P=0.812$ \\
\hline Surveillance colonoscopy performed & $42(84 \%)$ & $13(100 \%)$ & $P=0.333$ \\
\hline Presence of DALM & $30(60 \%)$ & $5(38.4 \%)$ & $P=0.257$ \\
\hline Cortison dependance & $14(28 \%)$ & $6(46 \%)$ & $P=0.245$ \\
\hline Immunotherapy & $1(0.2 \%)$ & $1(7 \%)$ & $P=0.298$ \\
\hline 5-ASA therapy & $33(66 \%)$ & $8(61.5 \%)$ & $P=0.400$ \\
\hline Immunosuppression & $9(18 \%)$ & $5(38 \%)$ & $P=0.153$ \\
\hline MSI & $5(1 \%)$ & $4(30 \%)$ & $P=0.072$ \\
\hline Active disease & $49(98 \%)$ & $13(100 \%)$ & $P=0.251$ \\
\hline PSC & $8(1.6 \%)$ & $4(30 \%)$ & $P=0.486$ \\
\hline Chemotherapy & $24(48 \%)$ & $11(84.6 \%)$ & $P=0.124$ \\
\hline Immunotherapy & $1(0.2 \%)$ & $1(7.7 \%)$ & $P=0.291$ \\
\hline Double colorectal cancer & $5(1 \%)$ & $1(7.7 \%)$ & $P=0.800$ \\
\hline Stenosis & $31(62 \%)$ & $7(53.8 \%)$ & $P=0.591$ \\
\hline Synchronous inflammation and cancer & $37(74 \%)$ & $10(77 \%)$ & $P=0.842$ \\
\hline Colitis extension & & & $P<0.001$ \\
\hline - Rectum & 2 & 0 & \\
\hline - Sigmoid colon & 5 & 2 & \\
\hline - Left-sided & 6 & 1 & \\
\hline - Pancolitis & 37 & 7 & \\
\hline - Ileocoeal & 0 & 3 & \\
\hline
\end{tabular}

$B M I$ body mass index, $M S I$ microsatellite instability, $P S C$ primary sclerosing cholangitis, DALM dysplasiaassociated lesion or mass, 5-ASA 5 aminosalicilate, $P y$ pack years 
Table 2 Patient characteristics of IBD patients with colorectal carcinoma versus sporadic colorectal carcinomas, Erlangen Registry of ColoRectal Carcinomas (ERCRC), $n=3773$

\begin{tabular}{|c|c|c|c|c|}
\hline & & $\begin{array}{l}\text { IBD-associated } \\
\text { CRC }(n=63) \\
n(\%)\end{array}$ & $\begin{array}{l}\text { Sporadic CRC } \\
(n=3710) \\
n(\%)\end{array}$ & $p$-value \\
\hline Age & Median (range) (years) & $45(22-80)$ & $66(18-99)$ & $<0.001$ \\
\hline \multirow[t]{2}{*}{ Sex } & Male & $35(56)$ & $2315(62.4)$ & 0.266 \\
\hline & Female & $28(44)$ & 1395 (37.6) & \\
\hline \multirow[t]{2}{*}{ ECOG* } & ECOG $0-1$ & $49(85)$ & $2882(84.8)$ & 0.953 \\
\hline & ECOG 2-4 & $9(16)$ & $518(15.2)$ & \\
\hline \multirow[t]{2}{*}{ ASA** } & ASA $1-2$ & $49(86)$ & $2422(75.2)$ & 0.062 \\
\hline & ASA 3-4 & $8(14)$ & $797(21.5)$ & \\
\hline \multirow[t]{3}{*}{ Tumor site } & Right colon & $25(40)$ & $863(23.3)$ & 0.008 \\
\hline & Left colon & $12(19)$ & $1060(28.6)$ & \\
\hline & Rectum & $26(41)$ & $1787(48.2)$ & \\
\hline \multirow[t]{2}{*}{ Emergency surgery } & Yes & $5(8)$ & $246(6.6)$ & 0.680 \\
\hline & No & $58(92)$ & $3464(93.4)$ & \\
\hline \multirow[t]{2}{*}{ Surgery } & TME/CME & $36(57)$ & $3701(99.8)$ & $<0.001$ \\
\hline & (Procto)colectomy & $27(43)$ & $9(0.2)$ & \\
\hline \multirow[t]{2}{*}{ Histological type } & Adenocarcinoma & $51(81)$ & $3370(90.8)$ & 0.007 \\
\hline & Other types*** & $12(19)$ & $340(9.2)$ & \\
\hline \multirow[t]{9}{*}{ Stage (UICC) } & Stage I & $16(26)$ & $748(20.2)$ & 0.334 \\
\hline & Stage II & $17(27)$ & $790(21.3)$ & \\
\hline & Stage III & $13(21)$ & 717 (19.3) & \\
\hline & Stage IV & $10(16)$ & $585(15.8)$ & \\
\hline & Stage y0 & 0 & $98(2.6)$ & \\
\hline & Stage yI & 0 & $191(5.2)$ & \\
\hline & Stage yII & $2(3)$ & $196(5.3)$ & \\
\hline & Stage yIII & $1(2)$ & $202(5.4)$ & \\
\hline & Stage yIV & $3(5)$ & $181(4.9)$ & \\
\hline \multirow[t]{2}{*}{ Distant metastases } & M0 & $50(79)$ & $2946(79.4)$ & 0.993 \\
\hline & M1 & $13(21)$ & 764 (20.6) & \\
\hline \multirow[t]{4}{*}{$\mathrm{R}$ classification } & R0 & $51(81)$ & 3097 (83.5) & 0.345 \\
\hline & $\mathrm{R} 1$ & $2(3)$ & $53(1.4)$ & \\
\hline & $\mathrm{R} 2$ & $8(13)$ & $515(13.9)$ & \\
\hline & $\mathrm{RX}$ & $2(3)$ & $45(1.2)$ & \\
\hline \multirow[t]{2}{*}{ Multimodal treatment } & Yes & $31(49)$ & $1826(50.8)$ & 0.998 \\
\hline & No & $32(51)$ & $1884(49.2)$ & \\
\hline
\end{tabular}

$I B D$ inflammatory bowel disease, $C R C$ colorectal carcinoma, ASA American Society of Anesthesiologists Classification, $T M E$ total mesorectal excision, $C M E$ complete mesorectal excision; *ECOG performance status in 315 patients unknown; **ASA missing in 497 patients; ***undifferentiated carcinoma, mucinous adenocarcinoma, signet ring cell carcinoma, medullary carcinoma, adenosquamous carcinoma. RX usually due to complete radio frequency ablation of liver metastases often rare histological subtypes of CRC (19\% versus 9.2\%) (Table $2 ; n=3773$ ).

Patients with $\mathrm{CD}$ were more often smokers than patients with UC. UC patients with IBD-CRC presented more frequently with a pancolitis than with localized left-sided colitis or proctitis. Sex, age at onset of CRC, duration of IBD, the presence of primary sclerosing cholangitis, immunosuppression, and rate of corticosteroid medication dependence were not statistically different between UC and CD patients. Sixtythree patients (98.4\%) presented with endoscopically active disease activity: one patient presented with endoscopic remission, $32(50 \%)$ had moderate endoscopic activity, and $30(48 \%)$ had severe endoscopic activity. The majority of the patients $(n=56 ; 88.9 \%)$ underwent complete surveillance colonoscopy. In these patients, CRC was diagnosed within 1.45 years (range $1-7$, SD 1.25 years) since the last surveillance colonoscopy. One patient with $\mathrm{UC}$ was found to have $\mathrm{CRC}$ in a colon without inflammation (quiescent IBD). In this patient, who also had PSC, random biopsies removed foci of adenocarcinoma on a DALM (dysplasia-associated 
lesion or mass) and no other foci of colorectal adenocarcinoma were found in the surgical specimen.

Forty-seven (74.6\%) patients had inflammatory activity synchronous with cancer; however, 16 patients (25.4\%) presented cancer even in the absence of overt endoscopic mucosal inflammation. Twenty-one patients did not receive IBD treatment despite endoscopic signs of inflammation. Forty-one patients $(65 \%)$ received a chemoprophylaxis and remission maintenance treatment with 5-aminosalycilate (mesalazin or sulfalazin, 5-ASA). Immunosuppressive treatment was administered in 17 patients (32\%): 7 (10.9\%) received azathioprin, $2(3.1 \%)$ infliximab, an immunosuppressive combination therapy was given in $5(7.8 \%)$ and cyclosporine in one patient (1.6\%), one patients took budesonide $(1.6 \%)$.

Twenty-three patients (35.9\%) received chemotherapy with 5-Fu or doublet chemotherapy of 5-Fu combined with oxaliplatin or irinotecan. Systemic immunotherapy with pembrolizumab was administered in 2 patients with microsatellite instability.

Forty-seven patients with IBD-associated CRC were matched with patients with sporadic CRC. In both groups, 11 of 47 patients developed postoperative complications. With respect to Clavien-Dindo classification (CDC), the distribution of the severity of complications did not differ significantly ( $p=0.633)$ - CDC grade I: 4 patients in each group; CDC grade II: 3 patients in each group; CDC grade III: 3 IBD patients and 2 sporadic CRC patients; CDC grade
IV: 1 IBD patient. However, 2 patients of the sporadic CRC group died postoperatively (CDC grade $\mathrm{V}$ ).

The median follow-up of all 3773 patients was 83 months (range 0-304); the median follow-up of the 1548 patients still alive was 145 months (range 40-304). For the 63 CED patients, the median follow-up was 36 months (range 1-228); for UC patients, 36 (range 1-216); and for CD patients, 24 months (range 3-228).

Overall survival did not differ between 63 IBD-associated CRC patients and 3710 sporadic CRC patients $(p=0.270$; Fig. 1). After matching 47 IBD-affected CRC patients with sporadic CRC patients, no differences in overall survival (OS) and disease-free survival (DFS) were found ( $p=0.99$ and $p=0.59$; Table 3; Figs. 2 and 3).

Of the 47 patients with IBD-associated CRC, a total of 9 patients developed distant metastases, 7 of them within 5 years. The 5 -year rate of distant metastasis was $17.5 \%$. The situation was similar in the 47 patients with sporadic CRC; 10 patients were diagnosed with distant metastases, 8 within 5 years; the 5 -year rate of distant metastasis was $18.5 \%(p=0.768)$. At the initial diagnosis of distant metastases, 6 IBD-associated CRC patients had metastases in a single organ and three patients had metastases in multiple organs. Similarly, sporadic CRC patients had solitary metastasis in 8 cases and multiple metastasis in 2 patients. The localization of the metastases was similar in both groups: liver in 2 patients each, lung in 3 and 6 patients, peritoneal metastases in 4 and 2 patients, others in 3 and 2 patients.
Fig. 1 Overall survival between IBD with CRC $(n=63$, green line) versus sporadic $\mathrm{CRC}$ ( $n=3710$, blue line), $p=0.270$

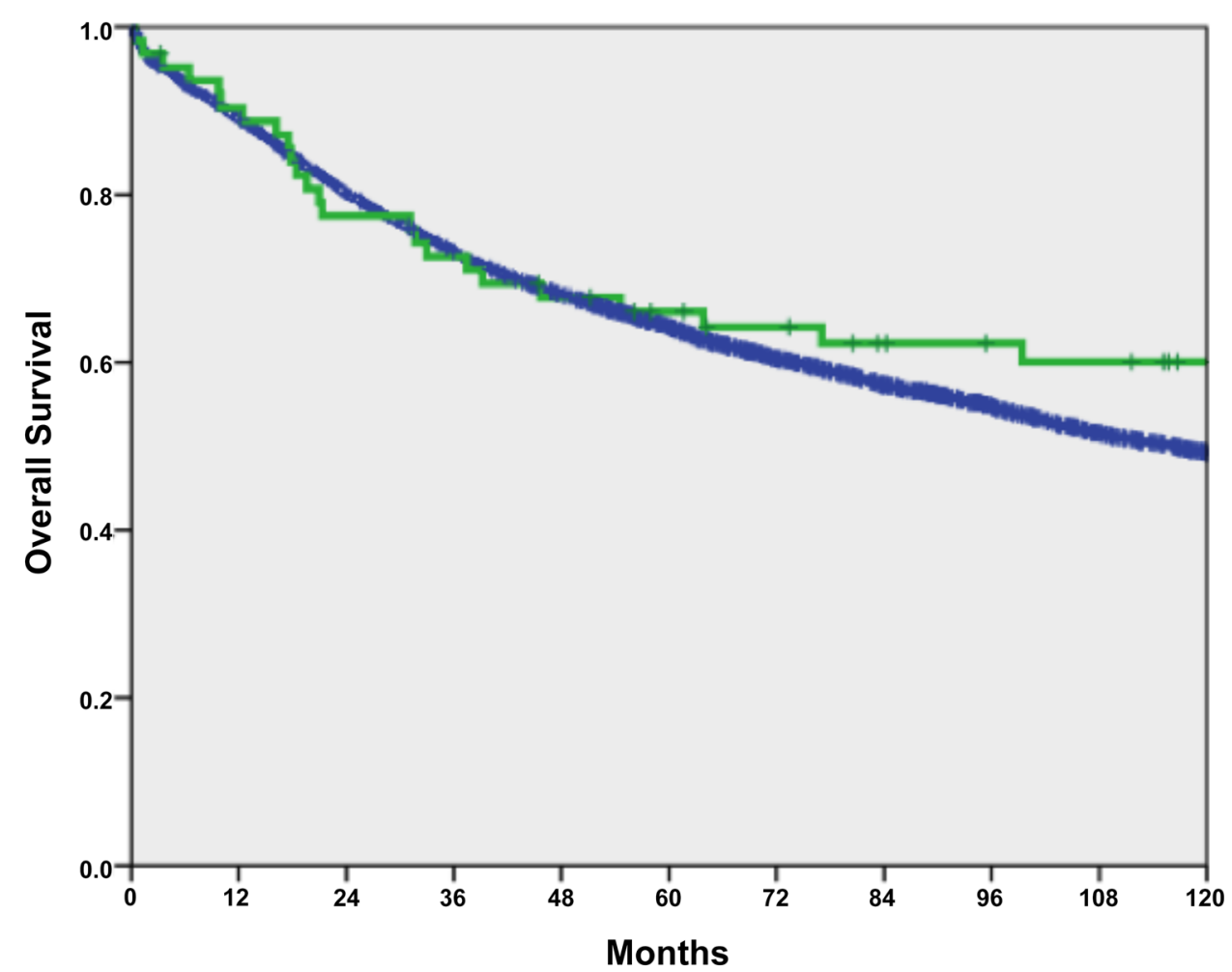


Table 3 Overall and diseasefree survival $(n=2 \times 47)$

\begin{tabular}{lllll}
\hline & $n$ & 3-year rate (95\% CI) & 5-year rate (95\% CI) & $p$ \\
\hline OS & & & & \\
IBD-associated CRC & 47 & $85.1(74.9-95.3)$ & $78.7(66.9-90.5)$ & 0.990 \\
Sporadic CRC & 47 & $87.2(77.6 / 96.8)$ & $80.9(69.7-92.1)$ & \\
DFS & & & & \\
IBD-associated CRC & 47 & $83.0(72.2-93.8)$ & $74.5(62.0-87.0)$ & 0.593 \\
Sporadic CRC & 47 & $74.5(62.0-87.0)$ & $70.2(57.1-83.3)$ & \\
\hline
\end{tabular}

There were two local recurrences among IBD-associated rectal neoplasm $(2 / 19 ; 11 \%)$ and one among sporadic rectal carcinomas $(1 / 19 ; 5 \% ; p=0.57)$.

\section{Discussion}

Over the last 30 years, the incidence of CRC in IBD has declined [15] and recent data estimate a cumulative CRC incidence for IBD of $1 \%$ at 10 years, $3 \%$ at 20 years, $7 \%$ at 30 years $[3,37]$. This may reflect the impact of surveillance strategies, better control of inflammation with maintenance therapy, and increased resection rates for DALM or dysplasia. Endoscopy is a milestone technique for surveillance in the care of patients with IBD and in the prevention of CRC. In our cohort, $85.9 \%$ of the patients underwent surveillance. Although recommended [2,38], none of the patients underwent dye-based chromoendoscopy; only surveillance based on random biopsies was performed during the study period. Even though surveillance was performed within the intervals recommended in the guidelines [1], CRC was diagnosed within a mean of 1.45 years after last endoscopy. The presence of cancer even in patients without overt signs of inflammation or malignancy on colonoscopy suggests the importance of histological evaluation and random biopsies in the surveillance of IBD patients, because fibrous tissue, pseudopolyps, and active inflammation can sometimes mask CRC (Figs. 4 and 5). According to such findings, we think that CRC screening should be improved and more effort should be done in applying cancer screening techniques like dye-based chromoendoscopy [39], artificial intelligence, and modern endoscopic imaging techniques [40].

In our cohort, $\mathrm{CRC}$ was diagnosed in patients with longstanding ulcerative colitis even in absence of endoscopically apparent inflammation. Such a finding was not emphasized in previous studies, but may suggest that inflammation patterns may trigger cancerogenesis in a complex and not yet completely understood way. Thus, colonic tissue may be at metachronous cancer risk even when inflammation can
Fig. 2 Overall survival of IBD-associated CRC $(n=47$, green line) versus sporadic CRC ( $n=47$, blue line) in the matched-pair analysis, $p=0.990$

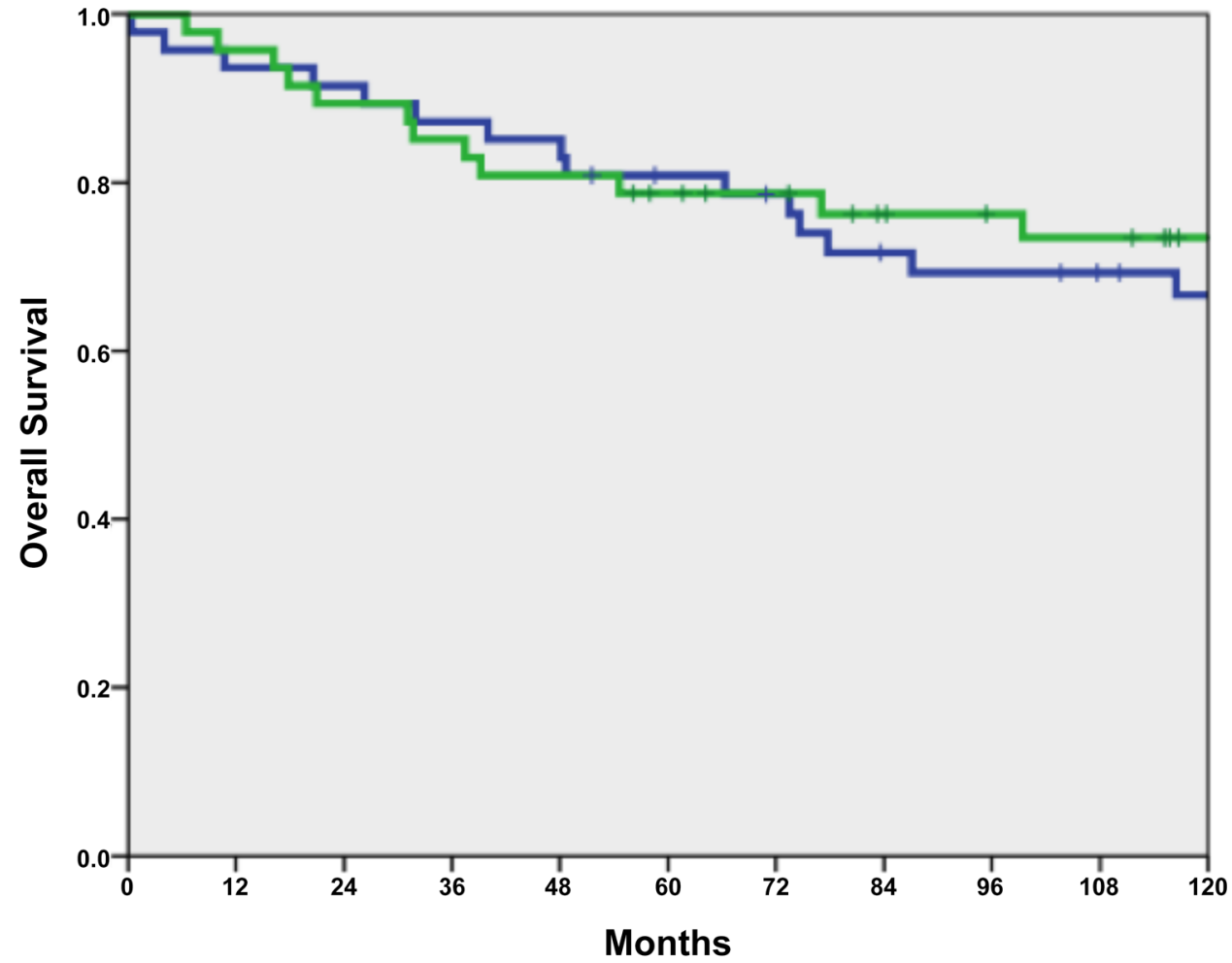


Fig. 3 Disease-free survival of IBD-associated CRC $(n=47$, green line) versus sporadic CRC ( $n=47$, blue line) in the matched-pair analysis, $p=0.593$

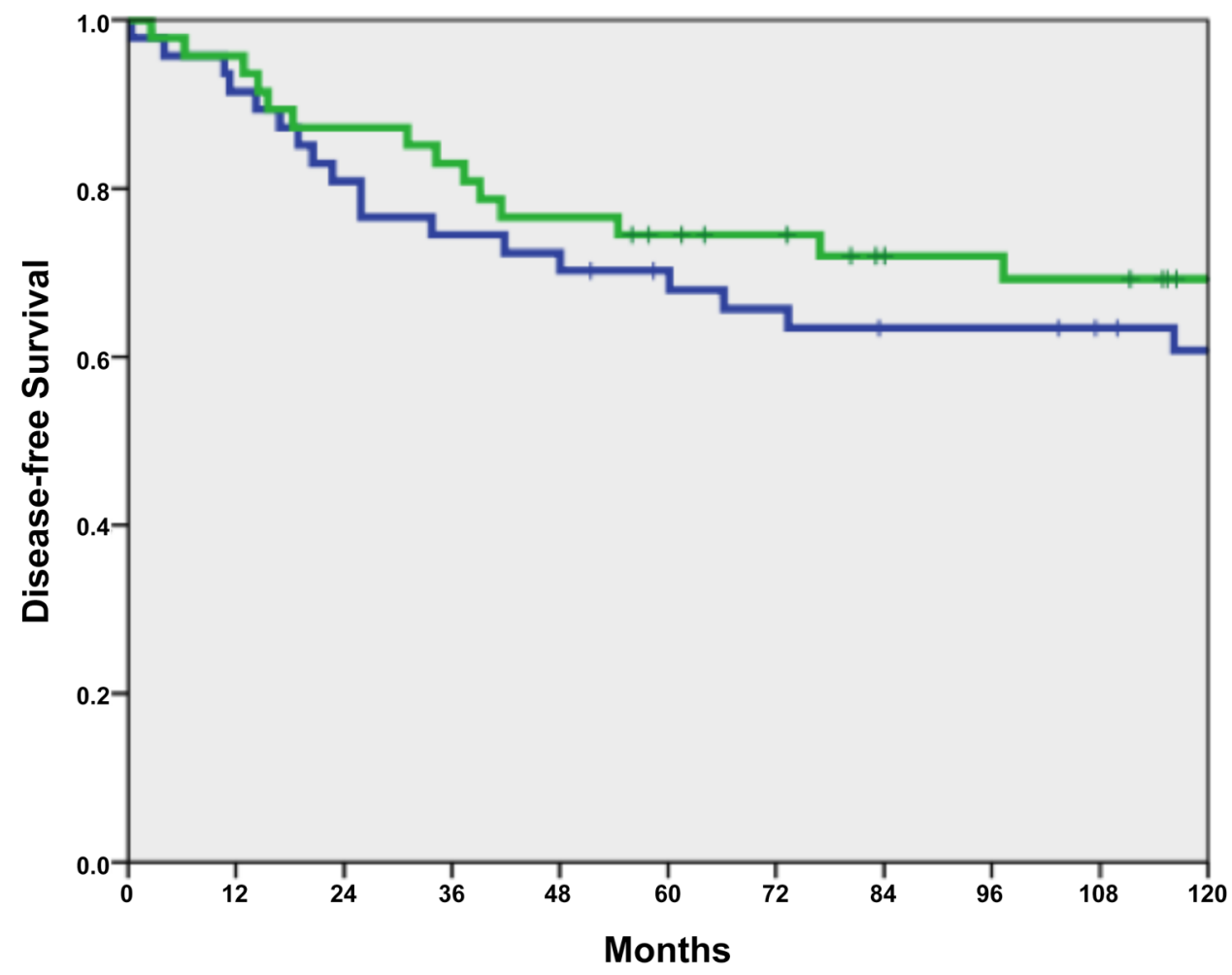

only be detected histologically [41]. Moreover, although a recently published retrospective survey reported that pseudopolyps do not increase the risk of malignancy [42], we found incidental CRC in biopsies from pseudopolyps of IBD patients without signs of severe inflammation. Pseudopolyps are probably not precancerous lesions per se, but are an indicator of past active relevant inflammation. Therefore, long-term follow-up (i.e., more than 5 years) should always be warranted in patients presenting with pseudopolyps.

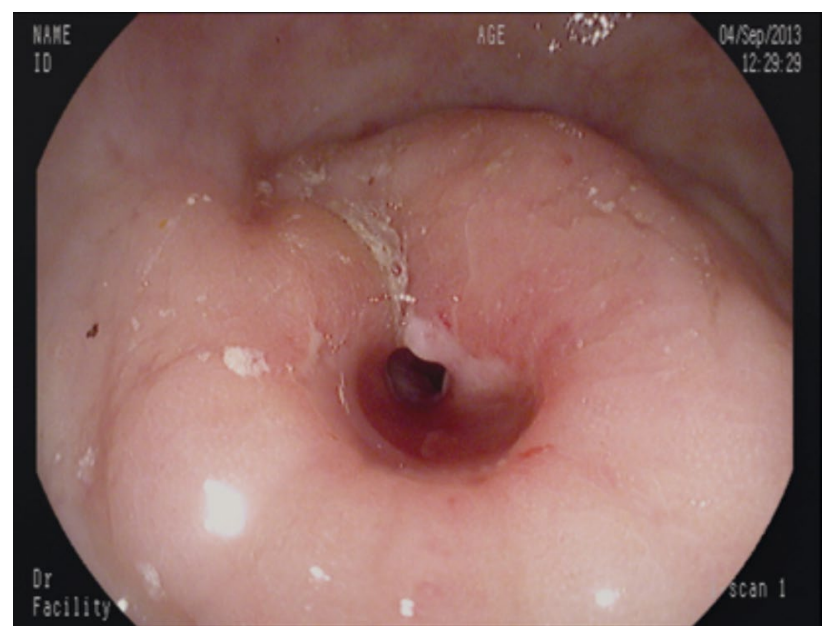

Fig. 4 IBD-associated CRC in a patient presenting with a colonic stenosis
In the literature, $\mathrm{CRC}$ has been shown to be diagnosed at an earlier stage in IBD patients, but survival is still worse compared to sporadic CRC and even the local recurrence risk was higher [43-46]. In our study, after excluding patients with distant metastasis and matching IBD-associated CRC with sporadic CRC, we found no difference in survival in patients after curative (R0) resection. Such findings underscore the importance of surveillance screening, because early diagnosis of a non-metastatic disease is associated with a prognosis comparable to that of sporadic CRC.

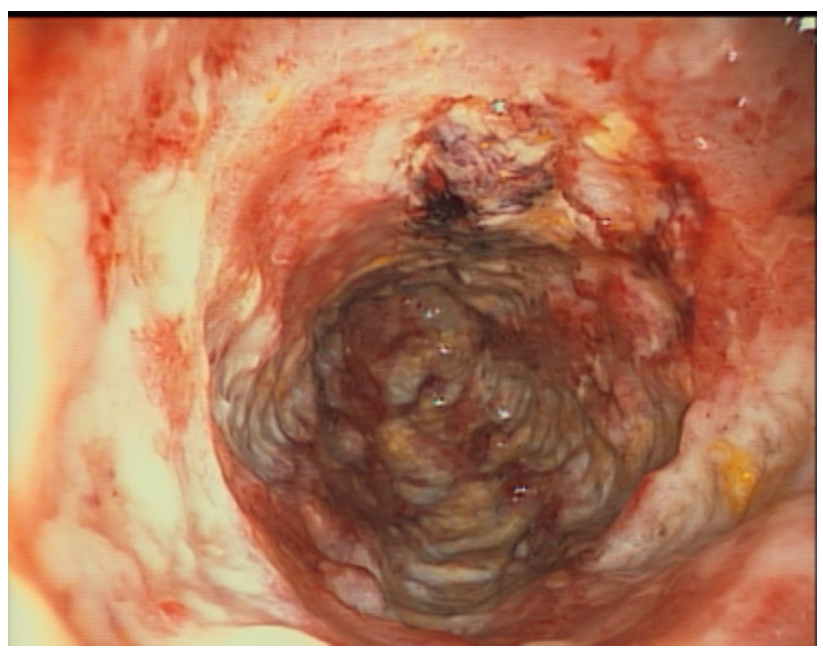

Fig. 5 IBD-associated CRC with macroscopic signs of active inflammation. In the biopsies, a CRC was diagnosed 
Table 4 Patient characteristics of $94(2 * 47)$ matched patients with colorectal carcinoma (match criteria in bold)

\begin{tabular}{|c|c|c|c|}
\hline & $\begin{array}{l}\text { IBD-associated CRC } \\
(n=47) \\
n(\%)\end{array}$ & $\begin{array}{l}\text { Sporadic CRC } \\
(n=47) \\
n(\%)\end{array}$ & $p$-value \\
\hline \multicolumn{4}{|l|}{ Age } \\
\hline Median (range) (years) & $46(22-80)$ & $51(21-79)$ & 0.166 \\
\hline \multicolumn{4}{|l|}{ Sex } \\
\hline Male & $30(64)$ & $30(64)$ & 1.0 \\
\hline Female & $17(36)$ & $17(36)$ & \\
\hline \multicolumn{4}{|l|}{ ECOG* } \\
\hline ECOG 0-1 & $40(91)$ & $38(86)$ & 0.739 \\
\hline ECOG 2-4 & $4(9)$ & $6(14)$ & \\
\hline \multicolumn{4}{|l|}{ ASA** } \\
\hline ASA $1-2$ & $35(88)$ & $39(91$ & 0.732 \\
\hline ASA 3-4 & $5(12)$ & $4(9)$ & \\
\hline \multicolumn{4}{|l|}{ Tumor site } \\
\hline Right colon & $18(38)$ & $18(38)$ & 1.0 \\
\hline Left colon & $10(21)$ & $10(21)$ & \\
\hline Rectum & $19(40)$ & $19(40)$ & \\
\hline \multicolumn{4}{|l|}{ Emergency surgery } \\
\hline Yes & $2(4)$ & $8(17)$ & 0.091 \\
\hline No & $45(96)$ & $39(83)$ & \\
\hline \multicolumn{4}{|l|}{ Surgery } \\
\hline TME/CME & $23(49)$ & $47(100)$ & $<0.001$ \\
\hline (Procto)colectomy & $24(51)$ & $0(0)$ & \\
\hline \multicolumn{4}{|l|}{ Histological type } \\
\hline Adenocarcinoma (8140/3) & $41(87)$ & $44(94)$ & \\
\hline Other histological types*** & $6(13)$ & $3(6)$ & 0.486 \\
\hline \multicolumn{4}{|l|}{ Pathological stage (UICC) } \\
\hline Stage I & $16(34)$ & $16(34)$ & 1.0 \\
\hline Stage II & $16(34)$ & $16(34)$ & \\
\hline Stage III & $12(26)$ & $12(26)$ & \\
\hline Stage yII & $2(4)$ & $2(4)$ & \\
\hline Stage yIII & $1(2)$ & $1(2)$ & \\
\hline \multicolumn{4}{|l|}{ Multimodal treatment } \\
\hline Yes & $16(34)$ & $13(28)$ & 0.509 \\
\hline NO & $31(66)$ & $34(72)$ & \\
\hline Neoadjuvant treatment for rectal cancer & $3 / 19$ & $3 / 19$ & 1.0 \\
\hline Adjuvant treatment & $15 / 47$ & $11 / 47$ & 0.356 \\
\hline Adjuvant treatment for rectal carcinoma stages II and III & $4 / 6$ & $5 / 6$ & 1.0 \\
\hline Adjuvant treatment for colon carcinoma stage III & $6 / 7$ & $5 / 7$ & 1.0 \\
\hline
\end{tabular}

$I B D$ inflammatory bowel disease, $C R C$ colorectal carcinoma, ASA American Society of Anesthesiologists Classification, TME total mesorectal excision, $C M E$ complete mesorectal excision. *ECOG performance status in 8 patients unknown; **ASA missing in 11 patients; ***undifferentiated carcinoma, mucinous adenocarcinoma, signet ring cell carcinoma

Usually CRC in IBD is diagnosed after about 10 years of disease duration; however, some data report early occurrence of CRC in IBD patients even after about 8 years [47]. In our study, 7 patients $(7.9 \%)$ were diagnosed with CRC within 8 years since the diagnosis of IBD. This early incidence may be due to early onset of IBD and tobacco abuse (as risk of early CRC) [48]; however, we could not confirm such finding in our cohort. Such data suggest that surveillance should also be tailored also according to risk factors, not only duration of disease.

Histological findings in patients with IBD-associated CRC differed from sporadic CRC. IBD patients were diagnosed with rarer histological subtypes of CRC such as mucinous adenocarcinoma, signet ring cell carcinoma, 
adenosquamous carcinoma, medullary carcinoma, and undifferentiated carcinoma, in $19 \%$ compared to $9.2 \%$ in sporadic $\mathrm{CRC}$. These histologic findings may explain a more aggressive behavior compared to the control CRC population, once metastases occur.

In this study, we did not compare survival between $C D$ and UC patients, because such data have already been included in a recent analysis of our registry database [49].

For 47 patients with IBD that were matched with sporadic CRC (Table 4), no statistically significant difference in disease-free or overall survival was detected. The newly published data of the English National Cancer Registry database show that IBD patients tend to have a worse survival compared with sporadic cases of CRC, in particular for stage III disease with regional lymph node metastasis, while no difference between stages I and II was demonstrated [50].

A limitation of this study is the retrospective nature of the study design and the limited number of patients included when compared to national cancer registries $[10,17,50,51]$. Another drawback is the inability for proper age matching of sporadic CRC with IBD-associated CRC. However, since sporadic CRC is extremely rare and sometimes associated with an unusual genetic oncogenic mutation at young onset, this inability for age matching is directly reflecting different tumor biology.

The strength of the study is that we could evaluate endoscopic findings in the majority of the cases (more than $85 \%$ underwent surveillance endoscopy) and thus establish the severity of IBD inflammation, duration of disease, and intensity or type of immunosuppression.

In conclusion, we confirmed previous studies that IBD-associated CRC occurs at younger ages. However, in our study population, we did not prove worse survival in comparison to sporadic CRC in a score-matched analysis after excluding patients with metastatic disease. The results emphasize the importance of surveillance and early detection of CRC in patients with IBD. This should primary be performed by surveillance endoscopy with targeted biopsies in time intervals that should be adjusted to risk factors, particularly with a family history for CRC, PSC, long-standing disease and smoking $[1,8,11]$. New surveillance techniques such as virtual chromoendoscopy, artificial intelligence, and cellular imaging should be further developed in order to optimize CRC screening [39, 40], as advanced CRC occurs also in patients who underwent correct guideline-based endoscopic surveillance.

Funding Open Access funding enabled and organized by Projekt DEAL.

\section{Declarations}

Conflict of interest The authors declare no competing interests.
Open Access This article is licensed under a Creative Commons Attribution 4.0 International License, which permits use, sharing, adaptation, distribution and reproduction in any medium or format, as long as you give appropriate credit to the original author(s) and the source, provide a link to the Creative Commons licence, and indicate if changes were made. The images or other third party material in this article are included in the article's Creative Commons licence, unless indicated otherwise in a credit line to the material. If material is not included in the article's Creative Commons licence and your intended use is not permitted by statutory regulation or exceeds the permitted use, you will need to obtain permission directly from the copyright holder. To view a copy of this licence, visit http://creativecommons.org/licenses/by/4.0/.

\section{References}

1. Annese V, Beaugerie L, Egan L, Biancone L, Bolling C, Brandts $\mathrm{C}$ et al (2015) European Evidence-based consensus: inflammatory bowel disease and malignancies. J Crohns Colitis 9:945-965

2. Farraye FA, Odze RD, Eaden J, Itzkowitz SH, McCabe RP, Dassopoulos T et al (2010) AGA medical position statement on the diagnosis and management of colorectal neoplasia in inflammatory bowel disease. Gastroenterology 138:738-745

3. Jess T, Rungoe C, Peyrin-Biroulet L (2012) Risk of colorectal cancer in patients with ulcerative colitis: a meta-analysis of population-based cohort studies. Clin Gastroenterol Hepatol Off Clin Pract J Am Gastroenterol Assoc 10:639-645

4. Eaden JA, Abrams KR, Mayberry JF (2001) The risk of colorectal cancer in ulcerative colitis: a meta-analysis. Gut 48:526-535

5. Ordás I, Eckmann L, Talamini M, Baumgart DC, Sandborn WJ (2012) Ulcerative colitis. Lancet (London England) 380:1606-1619

6. Rutter M, Saunders B, Wilkinson K, Rumbles S, Schofield G, Kamm M et al (2004) Severity of inflammation is a risk factor for colorectal neoplasia in ulcerative colitis. Gastroenterology 126:451-459

7. van der Sloot KWJ, Tiems JL, Visschedijk MC, Festen EAM, van Dullemen HM, Weersma RK et al Cigarette smoke increases risk for colorectal neoplasia in inflammatory bowel disease. LID - S1542-3565(21)00018-5 [pii] LID - https://doi.org/10.1016/j. cgh.2021.01.015

8. Beaugerie L, Svrcek M, Seksik P, Bouvier AM, Simon T, Allez M et al (2013) Risk of colorectal high-grade dysplasia and cancer in a prospective observational cohort of patients with inflammatory bowel disease. Gastroenterology 145(166-75):e8

9. Choi CR, Al Bakir I, Ding NJ, Lee GH, Askari A, Warusavitarne J et al (2019) Cumulative burden of inflammation predicts colorectal neoplasia risk in ulcerative colitis: a large single-centre study. Gut 68:414-422

10. Winther KV, Jess T, Langholz E, Munkholm P, Binder V (2004) Long-term risk of cancer in ulcerative colitis: a population-based cohort study from Copenhagen County. Clin Gastroenterol Hepatol Off Clin Pract J Am Gastroenterol Assoc 2:1088-1095

11. Moussata D, Allez M, Cazals-Hatem D, Treton X, Laharie D, Reimund JM et al (2018) Are random biopsies still useful for the detection of neoplasia in patients with IBD undergoing surveillance colonoscopy with chromoendoscopy? Gut 67:616-624

12. Yvellez OV, Rai V, Sossenheimer PH, Hart J, Turner JR, Weber C et al (2020) Cumulative histologic inflammation predicts colorectal neoplasia in ulcerative colitis: a validation study. Inflamm Bowel Dis

13. Brentnall TA, Haggitt RC, Rabinovitch PS, Kimmey MB, Bronner MP, Levine DS et al (1996) Risk and natural history of colonic neoplasia in patients with primary sclerosing cholangitis and ulcerative colitis. Gastroenterology 110:331-338 
14. Jess T, Gamborg M, Matzen P, Munkholm P, Sørensen TI (2005) Increased risk of intestinal cancer in Crohn's disease: a meta-analysis of population-based cohort studies. Am J Gastroenterol 100:2724-2729

15. Lutgens MW, van Oijen MG, van der Heijden GJ, Vleggaar FP, Siersema PD, Oldenburg B (2013) Declining risk of colorectal cancer in inflammatory bowel disease: an updated metaanalysis of population-based cohort studies. Inflamm Bowel Dis 19:789-799

16. Ali RA, Dooley C, Comber H, Newell J, Egan LJ (2011) Clinical features, treatment, and survival of patients with colorectal cancer with or without inflammatory bowel disease. Clin Gastroenterol Hepatol Off Clin Pract J Am Gastroenterol Assoc 9(584-9):e1-2

17. Watanabe T, Konishi T, Kishimoto J, Kotake K, Muto T, Sugihara K (2011) Ulcerative colitis-associated colorectal cancer shows a poorer survival than sporadic colorectal cancer: a nationwide Japanese study. Inflamm Bowel Dis 17:802-808

18. Farraye FA, Odze RD, Eaden J, Itzkowitz SH (2010) AGA technical review on the diagnosis and management of colorectal neoplasia in inflammatory bowel disease. Gastroenterology 138:746-74 (74 e1-4; quiz e12-3)

19. Ullman TA (2003) Dysplasia and colorectal cancer in Crohn's disease. J Clin Gastroenterol 36:S75-8 (discussion S94-6)

20. Gui X, Köbel M, Ferraz JG, Iacucci M, Ghosh S, Liu S et al (2020) Histological and molecular diversity and heterogeneity of precancerous lesions associated with inflammatory bowel diseases. J Clin Pathol 73:391-402

21. Baker AM, Cross W, Curtius K, Al Bakir I, Choi CR, Davis HL et al (2019) Evolutionary history of human colitis-associated colorectal cancer. Gut 68:985-995

22. Baker KT, Salk JJ, Brentnall TA, Risques RA (2018) Precancer in ulcerative colitis: the role of the field effect and its clinical implications. Carcinogenesis 39:11-20

23. Choi WT, Wen KW, Rabinovitch PS, Huang D, Mattis AN, Gill RM (2018) DNA content analysis of colorectal serrated lesions detects an aneuploid subset of inflammatory bowel diseaseassociated serrated epithelial change and traditional serrated adenomas. Histopathology 73:464-472

24. Svrcek M, Buhard O, Colas C, Coulet F, Dumont S, Massaoudi I et al (2010) Methylation tolerance due to an O6-methylguanine DNA methyltransferase (MGMT) field defect in the colonic mucosa: an initiating step in the development of mismatch repair-deficient colorectal cancers. Gut 59:1516-1526

25. Schulmann K, Mori Y, Croog V, Yin J, Olaru A, Sterian A et al (2005) Molecular phenotype of inflammatory bowel diseaseassociated neoplasms with microsatellite instability. Gastroenterology 129:74-85

26. Liu X, Goldblum JR, Zhao Z, Landau M, Heald B, Pai R et al (2012) Distinct clinicohistologic features of inflammatory bowel disease-associated colorectal adenocarcinoma: in comparison with sporadic microsatellite-stable and Lynch syndrome-related colorectal adenocarcinoma. Am J Surg Pathol 36:1228-1233

27. Pekow J, Hernandez K, Meckel K, Deng Z, Haider HI, Khalil A et al (2019) IBD-associated colon cancers differ in DNA methylation and gene expression profiles compared with sporadic colon cancers. J Crohns Colitis 13:884-893

28. Neufert C, Becker C, Türeci Ö, Waldner MJ, Backert I, Floh $\mathrm{K}$ et al (2013) Tumor fibroblast-derived epiregulin promotes growth of colitis-associated neoplasms through ERK. J Clin Investig 123:1428-1443

29. Hrabe JE, Byrn JC, Button AM, Zamba GK, Kapadia MR, Mezhir JJ (2014) A matched case-control study of IBD-associated colorectal cancer: IBD portends worse outcome. J Surg Oncol 109:117-121
30. Ording AG, Horváth-Puhó E, Erichsen R, Long MD, Baron JA, Lash TL et al (2013) Five-year mortality in colorectal cancer patients with ulcerative colitis or Crohn's disease: a nationwide population-based cohort study. Inflamm Bowel Dis 19:800-805

31. Hohenberger W, Weber K, Matzel K, Matzel K (2009). Papadopoulos T, Merkel S Standardized surgery for colonic cancer: complete mesocolic excision and central ligationtechnical notes and outcome

32. Merkel S, Weber K, Matzel KE, Agaimy A, Göhl J, Hohenberger W (2016) Prognosis of patients with colonic carcinoma before, during and after implementation of complete mesocolic excision

33. Brierly JDGM, Wittekind C (2017) TNM classification of malignant tumours, 8th edition. Wiley Blackwell, Oxford

34. Amin MBES, Greene FL, Schilsky RL, Gaspar LE, Washington MK, Sullivan DC, Brookland RK (2017) AJCC Cancer Staging Manual, 8th edition. Springer

35. Bosman FTCF, Hruban RH, Theise ND (eds) (2010) WHO classification of tumours of the digestive system, 4 th edition. WHO Press, Geneva, Switzerland

36. Clavien PA, Barkun J, de Oliveira ML, Vauthey JN, Dindo D, Schulick RD et al (2009) The Clavien-Dindo classification of surgical complications: five-year experience. Ann Surg 250:187-196

37. Selinger CP, Andrews JM, Titman A, Norton I, Jones DB, McDonald C et al (2014) Long-term follow-up reveals low incidence of colorectal cancer, but frequent need for resection, among Australian patients with inflammatory bowel disease. Clin Gastroenterol Hepatol Off Clin Pract J Am Gastroenterol Assoc 12:644-650

38. Resende RH, Ribeiro IB, de Moura DTH, Galetti F, Rocha RSP, Bernardo WM et al (2020). Surveillance in inflammatory bowel disease is chromoendoscopy the only way to go? A systematic review and meta-analysis of randomized clinical trials

39. Kandiah K, Subramaniam S, Thayalasekaran S, Chedgy FJ, Longcroft-Wheaton G, Fogg C et al (2021) Multicentre randomised controlled trial on virtual chromoendoscopy in the detection of neoplasia during colitis surveillance high-definition colonoscopy (the VIRTUOSO trial). Gut Sep;70(9):1684-1690

40. Rath T, Morgenstern N, Vitali F, Atreya R, Neurath MF (2020). Advanced endoscopic imaging in colonic neoplasia

41. Moss AC (2014). The meaning of low-grade inflammation in clinically quiescent inflammatory bowel disease

42. Mahmoud R, Shah SC, ten Hove JR, Torres J, Mooiweer E, Castaneda D et al (2019) No association between pseudopolyps and colorectal neoplasia in patients with inflammatory bowel diseases. Gastroenterology 156:1333-44.e3

43. Gearhart SL, Nathan H, Pawlik TM, Wick E, Efron J, Shore AD (2012) Outcomes from IBD-associated and non-IBD-associated colorectal cancer: a Surveillance Epidemiology and End Results Medicare study. Dis Colon Rectum 55:270-277

44. Renz BW, Thasler WE, Preissler G, Heide T, Khalil PN, Mikhailov $\mathrm{M}$ et al (2013) Clinical outcome of IBD-associated versus sporadic colorectal cancer: a matched-pair analysis. J Gastrointest Surg 17:981-990

45. Jensen AB, Larsen M, Gislum M, Skriver MV, Jepsen P, Nørgaard $B$ et al (2006) Survival after colorectal cancer in patients with ulcerative colitis: a nationwide population-based Danish study. Am J Gastroenterol 101:1283-1287

46. Larsen M, Mose H, Gislum M, Skriver MV, Jepsen P, Nørgård B et al (2007) Survival after colorectal cancer in patients with Crohn's disease: a nationwide population-based Danish follow-up study. Am J Gastroenterol 102:163-167

47. Lutgens MW, Vleggaar FP, Schipper ME, Stokkers PC, van der Woude CJ, Hommes DW et al (2008) High frequency of early colorectal cancer in inflammatory bowel disease. Gut $57: 1246-1251$ 
48. Cohen-Mekelburg S, Schneider Y, Gold S, Ghosh G, Rosenblatt R, Hajifathalian K et al (2019) Risk of early colorectal cancers needs to be considered in inflammatory bowel disease care. Dig Dis Sci 64:2273-2279

49. Vetter LE, Merkel S, Bénard A, Krautz C, Brunner M, Mittelstädt A et al (2020) Colorectal cancer in Crohn's colitis is associated with advanced tumor invasion and a poorer survival compared with ulcerative colitis: a retrospective dual-center study. Int J Colorectal Dis

50. Arhi C, Askari A, Nachiappan S, Bottle A, Arebi N, Athanasiou A et al (2020) Stage at diagnosis and survival of colorectal cancer with or without underlying inflammatory bowel disease: a population-based study. J Crohns Colitis

51. Jess T, Simonsen J, Jørgensen KT, Pedersen BV, Nielsen NM, Frisch MSD (2012) Decreasing risk of colorectal cancer in patients with inflammatory bowel disease over 30 years. Gastroenterology 143:375-81 (e1; quiz e13-4)

Publisher's Note Springer Nature remains neutral with regard to jurisdictional claims in published maps and institutional affiliations. 